Удк 541.13

\title{
ЭЛЕКТРОХИМИЧЕСКОЕ ОКИСЛЕНИЕ ГРУБОГО РАСТИТЕЛЬНОГО СЫРья
}

\author{
() Е.В. Мамонтова* М.П. Зяблицева
}

Вятская государственная сельскохозяйственная академия, Октябрьский пр., 133, Киров, 610017 (Россия), e-mail: amel-@mail.ru

Исследован процесс электрохимического окисления грубого растительного сырья: выполнено математическое планирование эксперимента, реализованы опыты, построены математические модели. Определены оптимальные условия обработки: температура электролита $70{ }^{\circ} \mathrm{C} ; \mathrm{pH}$ электролита - обработка ржаной соломы и березовых опилок при $\mathrm{pH}=8,0-10,0$ (25\% электричества), затем при $\mathrm{pH}=4,0-6,0$ (75\% электричества), осиновых опилок - при $\mathrm{pH}=4,0-6,0$;

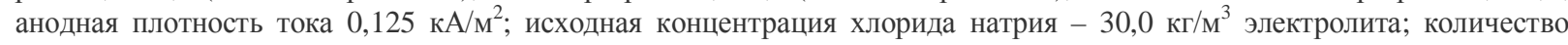
электричества 0,9 кА·ч/кг сырья.

После электрохимической обработки ржаной соломы, березовых и осиновых опилок определены редуцирующие вещества (6,0-6,3 масс. \% от сырья), глюкоза (4,5-5,0 масс. \% от сырья), кислородсодержащие соединения хлора $\left(\mathrm{ClO}^{-}\right.$менее $0,001 \mathrm{\kappa г} / \mathrm{m}^{3}$ электролита, $\mathrm{ClO}_{3}^{-}-0,014-0,019 \mathrm{\kappa r} / \mathrm{m}^{3}$ электролита), масса остаточного твердого вещества (6080 масс. \% от сырья), рутений и титан (отсутствие).

Метод планируется для использования в кормопроизводстве с целью устранения дебаланса по сахарам в рационе кормов сельскохозяйственных животных.

Ключевые слова: электролиз, окисление, солома, древесные опилки, редуцирующие вещества, глюкоза.

\section{Введение}

Питательная ценность грубого растительного сырья остается малодоступной для животных вследствие недостаточности окисления его в желудочно-кишечном тракте (усвояемость соломы не превышает $10 \%)$. Это обусловлено наличием в грубом растительном сырье лигнина, связанного с целлюлозой и другими структурными компонентами лигниноуглеводного комплекса (ЛУК) эфироподобными связями.

Методы химического и биохимического окисления грубого растительного сырья приводят к загрязнению агрессивными веществами продуктов обработки. Электрохимический метод позволяет проводить окисление грубого растительного сырья в растворе хлорида натрия продуктами гидролиза электрохимически генерируемого хлора (хлорноватистая кислота и гипохлорит натрия). На оксидном рутениевотитановом аноде (ОРТА) в растворе хлорида натрия при потенциале выделения хлора окисление сахаров и органических компонентов грубого растительного сырья практически не происходит [1].

Цель работы - окисление грубого растительного сырья при электролизе раствора хлорида натрия.

\section{Экспериментальная часть}

Исследование процесса электрохимического окисления измельченного до 2-4 мм грубого растительного сырья (ржаная солома, опилки березовые и осиновые с территории Кировской области, срок заготовки материала - август 2009-2012 г.) проводили в бездиафрагменном электролизере с перемешиванием, в качестве электролита использовали раствор хлорида натрия, анод - ОРТА, катод - титан. Величину рН

Мамонтова Екатерина Владимировна - старший преподаватель, e-mail: amel-@mail.ru Зяблицева Мария Петровна - кандидат технических наук, доцент, e-mail:_elektrohimija12@yandex.ru корректировали растворами $\mathrm{HCl}$ и $\mathrm{NaOH}$. Основные процессы, протекающие при электролизе раствора хлорида натрия на ОРТА:

\footnotetext{
* Автор, с которым следует вести переписку.
} 


$$
\begin{gathered}
\mathrm{Cl}^{-}-\mathrm{e} \rightarrow \mathrm{Cl} \\
\mathrm{Cl}+\mathrm{Cl} \rightarrow \mathrm{Cl}_{2} .
\end{gathered}
$$

В объеме электролита хлор подвергается гидролизу:

$$
\mathrm{Cl}_{2}+\mathrm{H}_{2} \mathrm{O} \rightarrow \mathrm{HClO}+\mathrm{HCl}
$$

Хлорноватистая кислота является окислителем грубого растительного сырья, но может вступать в реакцию и со щелочью, образующейся в прикатодном пространстве:

$$
\mathrm{HClO}+\mathrm{OH}^{-} \rightarrow \mathrm{ClO}-+\mathrm{H}_{2} \mathrm{O}
$$

что приводит к получению другого окислителя органических соединений - гипохлорита натрия:

$$
\mathrm{Na}^{+}+\mathrm{ClO}^{-} \leftrightarrow \mathrm{NaClO}
$$

Определение влияния условий электролиза и природы перерабатываемого сырья на выход продуктов окисления - многофакторная задача. С целью сокращения количества экспериментов построен 3-уровневый ортогональный план [2]. Параметром оптимизации задана массовая доля редуцирующих веществ (РВ), факторами - условия процесса. Исследуемые переменные и их значения представлены в таблице 1.

Фактор рН на втором уровне: обработка при рН 8,0-10,0 (расход 25\% электричества), затем при $\mathrm{pH}=4,0-6,0$ (расход 75\% электричества).

Для построения матрицы математического планирования эксперимента в колонках $\mathrm{X}_{1}, \mathrm{X}_{2}, \mathrm{X}_{3}$ записывали полный 3-уровневый факторный эксперимент. Уровень фактора $\mathrm{X}_{4}$ получали сложением уровней факторов $\mathrm{X}_{1}$ и $\mathrm{X}_{3}$ по модулю 3 , уровень фактора $\mathrm{X}_{5}$ - сложением уровня фактора $\mathrm{X}_{1}$ с удвоенным уровнем

\begin{tabular}{|c|c|c|c|c|c|}
\hline \multirow[b]{2}{*}{$\begin{array}{l}\text { Номер } \\
\text { уровня }\end{array}$} & \multicolumn{5}{|c|}{ Значения факторов на уровнях } \\
\hline & $\begin{array}{c}\text { Температура } \\
\text { электролита, }{ }^{\circ} \mathrm{C} \\
\mathrm{X}_{1}\end{array}$ & $\begin{array}{c}\mathrm{pH} \\
\text { электролита } \\
\mathrm{X}_{2}\end{array}$ & $\begin{array}{c}\text { Исходная концентрация } \\
\mathrm{NaCl}, \text { кг/м }{ }^{3} \text { электролита } \\
\mathrm{X}_{3}\end{array}$ & $\begin{array}{c}\text { Анодная плот- } \\
\text { ность тока, кА/м } \\
\mathrm{X}_{4}\end{array}$ & $\begin{array}{c}\text { Количество электри- } \\
\text { чества, кА·ч/кг сырья } \\
\mathrm{X}_{5}\end{array}$ \\
\hline 1 & 50 & $4,0-6,0$ & 15,0 & 0,125 & 0,6 \\
\hline 2 & 70 & $\begin{array}{c}8,0-10,0 \\
4,0-6,0\end{array}$ & 30,0 & 0,250 & 0,9 \\
\hline 3 & 90 & $8,0-10,0$ & 45,0 & 0,500 & 1,2 \\
\hline
\end{tabular}
фактора $\mathrm{X}_{3}$ по тому же модулю. Основание модуля выбирали равным числу уровней [2]. Матрица включала 27 экспериментов. Согласно матрице математического планирования реализованы опыты и выполнены анализы продуктов переработки.

Таблица 1. Интервалы варьирования переменных и значения факторов на уровнях

Анализ продуктов окисления древесных опилок и ржаной соломы проводили качественно методом ИК-спектроскопии (с предварительным упариванием рабочих растворов до сухой соли и экстракцией продуктов окисления четыреххлористым углеродом, содержание остаточной воды в образцах не превышало 1,0 масс. \%) и количественно. Эбулиостатическим методом определены РВ [3], фотоколориметрическим глюкоза, титриметрическим - кислородсодержащие соединения хлора, гравиметрическим - масса остаточного твердого вещества. РФА выполнен на наличие рутения и титана в остаточном твердом веществе. Результаты представлены в таблице 2 и на рисунках 1-4.

\section{Обсуждение результатов}

Результаты, полученные при изучении влияния условий электрохимического окисления грубого растительного сырья на выход РВ, обрабатывали математически. Построены математические модели процессов электрохимического окисления ржаной соломы, березовых и осиновых опилок. Анализ математических моделей показал, что при окислении ржаной соломы из девяти построенных математических моделей [4] оптимальной является модель третьего порядка: 


$$
\begin{gathered}
Y=1,580-0,141 \cdot X_{1}+0,041 \cdot X_{2}+0,077 \cdot X_{3}-1,467 \cdot X_{4}-3,119 \cdot X_{5}-0,002 \cdot X_{6}+0,007 \cdot X_{7}-0,001 \cdot X_{8}+ \\
+0,124 \cdot X_{10}-0,011 \cdot X_{11}+0,014 \cdot X_{14}-0,012 \cdot X_{17}+0,083 \cdot X_{19}-0,002 \cdot X_{6}+0,246 \cdot X_{20}+0,000 \cdot X_{25}-0,001 \cdot X_{29}+ \\
0,000 \cdot X_{32}-0,009 \cdot X_{35}+0,001 \cdot X_{39}-0,001 \cdot X_{45}-0,000 \cdot X_{51}+0,007 \cdot X_{54}
\end{gathered}
$$

где $\mathrm{Y}$ - массовая доля РВ от сырья, \%; $\mathrm{X}_{1}, \mathrm{X}_{2}, \mathrm{X}_{3}, \mathrm{X}_{4}, \mathrm{X}_{5}$ - значения факторов (см. табл. 1).

Состав расчетных факторов при статистической достоверности со степенью вероятности 0,95 представлен в [4]. Среднеквадратичное отклонение результатов расчета от экспериментально полученных данных не превышало $0,14 \%$.

Математические модели электрохимического окисления ржаной соломы, березовых и осиновых опилок позволили рассчитать выход РВ в промежуточных точках интервалов варьирования переменных, учесть взаимное влияние факторов на выход РВ, определить оптимальные условия процесса электрохимического окисления грубого растительного сырья, построить графики зависимостей выхода РВ от факторов.

Сравнительная оценка полученных результатов показала, что оптимальные условия процесса электрохимического окисления ржаной соломы, березовых и осиновых опилок по многим факторам совпадают: температура электролита $70{ }^{\circ} \mathrm{C}, \mathrm{pH}$ электролита - обработка ржаной соломы и березовых опилок при $\mathrm{pH}=8,0-10,0$ (25\% электричества), затем при $\mathrm{pH}=4,0-6,0$ (75\% электричества), осиновых опилок - при $\mathrm{pH}=4,0-6,0$, анодная плотность тока 0,125 кА/ ${ }^{2}$, исходная концентрация хлорида натрия в электролите 30,0 кг $/ \mathrm{M}^{3}$, количество электричества 0,9 кА·ч/кг сырья.

В спектре вытяжки экстрактов из растворов после электрохимического окисления грубого растительного сырья обнаружены широкие полосы поглощения 3400 и 1620-1680 см${ }^{-1}$ и слабые - 1080-1100 см${ }^{-1}$. Полосы поглощения $3400 \mathrm{~cm}^{-1}$ отнесены к валентным колебаниям гидроксогрупп. Полосы поглощения 1620$1680 \mathrm{~cm}^{-1}$ соответствуют асимметричным валентным колебаниям карбоксильной группы, полосы поглощения 1080-1100 см с $^{-1}$ отвечают валентным колебаниям групп - C-О- (эфирные группировки). В спектре присутствуют полосы поглощения 1420 и 1200-1300 $\mathrm{cm}^{-1}$, соответствующие взаимодействию между плоскими деформационными колебаниями гидроксогрупп и колебаниями карбонильных групп.

В составе растворов после электрохимической обработки ржаной соломы и древесных опилок в оптимальном режиме определена глюкоза с максимальным выходом 4,5-5,0 масс. \% от сырья, кислородсодержащие соединения хлора (табл. 2) и масса остаточного твердого вещества - 60-80 масс. \% от сырья, титана и рутения в остаточном твердом веществе не обнаружено.

Зависимость выхода РВ от $\mathrm{pH}$ электролита при окислении ржаной соломы и древесных опилок представлена в таблице 2.

Для березовых опилок и ржаной соломы обработка в щелочной, а затем в кислой среде более предпочтительна - выход РВ превышает 6,0 масс. \% от сырья. По-видимому, это связано с раздревеснением (разрушением ЛУК) в щелочной среде, с последующим гидролизом клетчатки в кислой среде. Выход РВ при электрохимическом окислении осиновых опилок в кислой среде и в два этапа (в щелочной, а затем в кислой среде) практически совпадает.

Все виды грубого растительного сырья при температуре $50-60{ }^{\circ} \mathrm{C}$ окисляются с небольшим выходом PB (2,5-3,0 масс. \% от сырья); при $90{ }^{\circ} \mathrm{C}$ выход РВ меньше, чем при $70{ }^{\circ} \mathrm{C}$, что, на наш взгляд, обусловлено деструктивным окислением органических соединений. Максимальный выход РВ (более 6,0 масс. \% от сырья) рассчитан по математическим моделям при $80{ }^{\circ} \mathrm{C}$ (см. рис. 1).

Таблица 2. Показатели окисления грубого растительного сырья в зависимости от рН электролита при прочих оптимальных условиях процесса

\begin{tabular}{c|c|c|c|c|c|c}
\hline \multirow{2}{*}{$\mathrm{pH}$} & \multicolumn{3}{|c|}{ Выход РВ, масс.\% от сырья } & \multicolumn{3}{c}{ Концентрация $\mathrm{ClO}_{3}^{-}$, г/ ${ }^{3}$} \\
\cline { 2 - 7 } & $\begin{array}{c}\text { Ржаная } \\
\text { солома }\end{array}$ & $\begin{array}{c}\text { Березовые } \\
\text { опилки }\end{array}$ & $\begin{array}{c}\text { Осиновые } \\
\text { опилки }\end{array}$ & $\begin{array}{c}\text { Ржаная } \\
\text { солома }\end{array}$ & $\begin{array}{c}\text { Березовые } \\
\text { опилки }\end{array}$ & $\begin{array}{c}\text { Осиновые } \\
\text { опилки }\end{array}$ \\
\hline $4,0-6,0$ & $4,5-4,9$ & $4,4-5,0$ & $6,0-6,2$ & $8-12$ & $7-12$ & $10-13$ \\
$8,0-10,0$ & $2,6-3,2$ & $2,9-3,2$ & $3,0-3,4$ & $24-33$ & $22-33$ & $28-35$ \\
Последовательно: & $6,0-6,1$ & $6,0-6,2$ & $6,0-6,3$ & $14-17$ & $14-16$ & $18-19$ \\
$8,0-10,0$ & $\ldots$ & $\ldots$ & $\ldots$ & $\ldots$ & $\ldots$ & $\ldots$ \\
$4,0-6,0$ & $\ldots$ & $\ldots$ & $\ldots$ & $\ldots$ & $\ldots$ & $\ldots$ \\
\hline
\end{tabular}


Для ржаной соломы и древесных опилок понижение исходной концентрации хлорида натрия с 30,0 до 15,0 кг/м ${ }^{3}$ при прочих оптимальных условиях (рис. 2) несколько (на $0,5-0,7$ масс. \% от сырья) повышает выход РВ, но приводит к росту напряжения на электролизере (на $0,2-0,3$ В) и соответственно увеличивает расход электроэнергии. Повышение концентрации хлорида натрия с 30,0 до 45,0 кг/м ${ }^{3}$ не приводит к заметным изменениям выхода РВ и напряжения на электролизере. Изменение концентрации хлорида натрия при проведении экспериментов вследствие корректировки $\mathrm{pH}$ и рекуперации хлорид-ионов в процессе окисления грубого растительного сырья практически не происходило.

Максимальный (более 6,0 масс. \% от сырья) выход РВ и для соломы, и для древесных опилок получен в области низких анодных плотностей тока (рис. 3), с увеличением анодной плотности тока от 0,125 до 0,500 кА $/ \mathrm{M}^{2}$ идет резкое (на 3,0-4,0 масс. \% от сырья) снижение выхода РВ. В растворах хлоридов при потенциале выделения хлора на ОРТА анодный процесс окисления органических соединений затруднен (практически не протекает) и не может дать настолько заметного эффекта [1]. Наблюдаемое снижение выхода $\mathrm{PB}$, возможно, обусловлено увеличением содержания в растворе ионов $\mathrm{ClO}^{-}$и их последующим окислением до ионов $\mathrm{ClO}_{3}^{-}$; подтверждением высказанного предположения является повышение концентраций кислородсодержащих соединений хлора в растворе при увеличении анодной плотности тока.

Исследование зависимости выхода РВ от количества электричества позволило установить (рис. 4), что при расходе электричества 0,6 кА·ч/кг сырья раздревеснение и гидролиз всех видов грубого растительного сырья недостаточны: выход РВ не превышает 3,5 масс. \% от сырья. Увеличение количества электричества от 0,9 кА·ч/кг сырья до 1,2 кА·ч/кг сырья мало влияет на выход РВ (повышение на 0,2-0,4 масс. \% при окислении ржаной соломы и березовых опилок и снижение на 0,5 масс. \% при окислении осиновых опилок), но приводит к существенному увеличению расхода электричества. Небольшое изменение выхода PB при значительном росте количества электричества, вероятно, связано с процессами деструктивного окисления органических соединений в объеме электролита.

Концентрация кислородсодержащих соединений хлора в растворе практически не зависит от вида используемого грубого растительного сырья; при оптимальных условиях процесса окисления (см. табл. 2) содержание ионов $\mathrm{ClO}_{3}{ }^{-}$в растворе изменялось от $0,008 \mathrm{\kappa г} / \mathrm{M}^{3}$ электролита (кислая среда) до $0,350 \mathrm{\kappa r} / \mathrm{M}^{3}$ электролита (щелочная среда). Концентрация ионов $\mathrm{ClO}^{-}$при обработке всех видов грубого растительного сырья не превышала 0,001 кг/ $\mathrm{M}^{3}$ электролита. Повышение анодной плотности тока, концентрации хлорида натрия, количества пропущенного электричества, $\mathrm{pH}$ электролита, снижение температуры приводят к увеличению содержания кислородсодержащих соединений хлора в электролите.

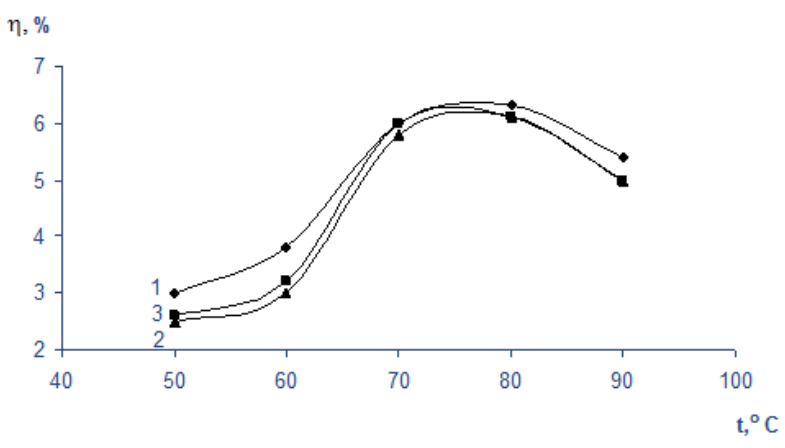

Рис. 1. Зависимость выхода редуцирующих веществ от температуры (1 - осиновые опилки, 2 - ржаная солома, 3 - березовые опилки). Условия: $\mathrm{pH} 8,0-10,0$ (25\% электричества), затем pH 4,0-6,0 (75\% электричества) - обработка ржаной соломы и березовых опилок, $\mathrm{pH} 4,0-6,0$ обработка осиновых опилок; анодная плотность тока $0,125 \mathrm{\kappa A} / \mathrm{M}^{2}$; концентрация хлорида натрия 30,0 кг/ $\mathrm{M}^{3}$ электролита; количество электричества 0,9 кА·ч/кг сырья

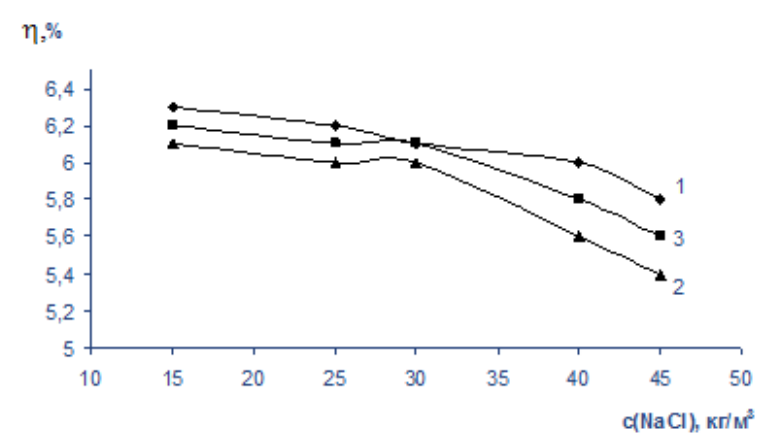

Рис. 2. Зависимость выхода редуцирующих веществ от концентрации хлорида натрия (1 - осиновые опилки, 2 - ржаная солома, 3 - березовые опилки). Условия: температура $70{ }^{\circ} \mathrm{C}, \mathrm{pH} 8,0-10,0$ (25\% электричества), затем $\mathrm{pH}$ $4,0-6,0$ (75\% электричества) - обработка ржаной соломы и березовых опилок, $\mathrm{pH} 4,0-6,0$ обработка осиновых опилок; анодная плотность тока $0,125 \mathrm{\kappa A} / \mathrm{M}^{2} ;$ количество электричества 0,9 кА·ч/кг сырья 


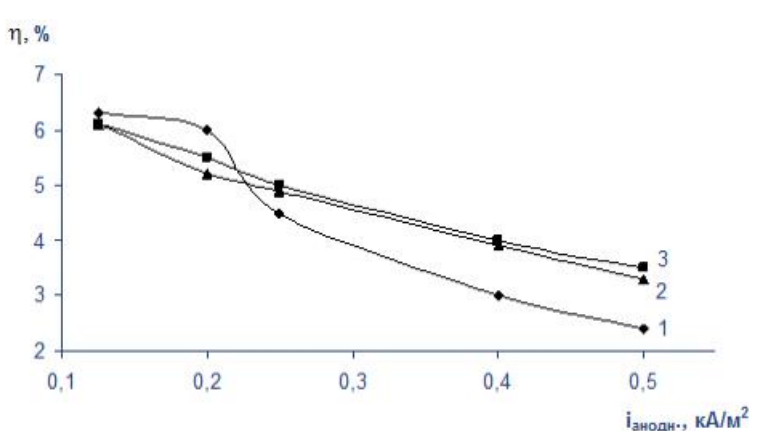

Рис. 3. Зависимость выхода редуцирующих веществ от анодной плотности тока (1 - осиновые опилки, 2 - ржаная солома, 3 - березовые опилки). Условия: температура $70{ }^{\circ} \mathrm{C}, \mathrm{pH} 8,0-10,0$ (25\% электричества), затем $\mathrm{pH}$ 4,0-6,0 (75 \% электричества) - обработка ржаной соломы и березовых опилок, рН 4,0-6,0 - обработка осиновых опилок; концентрация хлорида натрия 30,0 кг/ ${ }^{3}$ электролита; количество электричества 0,9 кА·ч/кг сырья

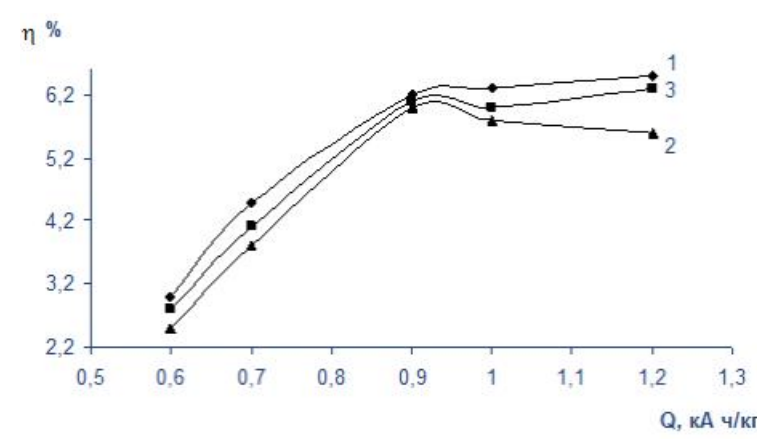

Рис. 4. Зависимость выхода редуцирующих веществ от количества электричества (1 - осиновые опилки, 2 - ржаная солома, 3 - березовые опилки). Условия: температура $70{ }^{\circ} \mathrm{C}, \mathrm{pH} 8,0-10,0$ (25\% электричества), затем $\mathrm{pH}$ 4,0-6,0 (75\% электричества) - обработка ржаной соломы и березовых опилок, $\mathrm{pH} 4,0-6,0$ обработка осиновых опилок; анодная плотность тока 0,125 кА/ ${ }^{2}$; концентрация хлорида натрия 30,0 кг/ $\mathrm{M}^{3}$ электролита

\section{Заключение}

Для процесса электрохимического окисления ржаной соломы и древесных (березовых, осиновых) опилок разработаны оптимальные условия, позволяющие получить выход редуцирующих веществ 6,06,3 масс. \%, в том числе глюкозы 4,5-5,0 масс. \% от сырья, при концентрациях ионов $\mathrm{ClO}^{-}$менее 0,001

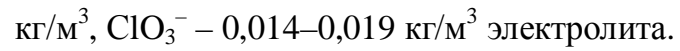

Разработанный метод планируется для использования в кормопроизводстве с целью устранения дебаланса по сахарам в рационе кормов крупнорогатого скота, птицы, свиней.

\section{Список литературы}

1. Авруцкая И.А., Мухина И.Б., Архипова Т.А. Поведение органических компонентов грубого растительного сырья при электролизе хлоридных растворов // Электрохимия. 1996. Т. 32, №1. С.75-78.

2. Рузинов Л.П. Планирование эксперимента в химии и химической технологии. М., 1980. 280 с.

3. Выродова Л.П., Морозова С.Ф., Дегтярёва Н.Н. Инструкция по химико-технологическому контролю гидролизного производства, этилового спирта, кормовых дрожжей и технического фурфурола // Сборник трудов ВНИИ Гидролиз. Л., 1987. С. 45-52.

4. Зяблицева Е.В., Ряттель А.В., Зяблицева М.П., Лобастова Е.В. Электрохимическое окисление соломы // Современные твердофазные технологии: теория, практика и инновационный менеджмент. Тамбов, 2010. С. $249-251$.

5. Патент 2352140 (РФ). Способ обработки грубых кормов / М.П. Зяблицева, Л.Н. Толмачёва, Н.Б. Багаева, Е.В. Зяблицева, Е.В. Лобастова. 2009.

6. Патент 2352184 (РФ). Установка обработки грубых кормов / М.П. Зяблицева, Е. В. Зяблицева. 2009. 
Mamontova E.V., Zyablitseva M.P. THE ELECTROCHEMICAL OXIDATION OF ROUGH PLANT RAW MATERIALS

Vyatka State Agricultural Academy, Oktiabr'skii ave., 133, Kirov, 610017 (Russia), e-mail: amel-@mail.ru

Research result of process of electrochemical oxidation of rough plant raw materials: the mathematical planning of experiments, the researches, the creation of mathematical models. Authors defined optimum conditions of processing: temperature of the electrolyte is 70 degrees, the $\mathrm{pH}$ of electrolyte - treatment of rye straw and birch sawdust at $\mathrm{pH}$ equal $8,0-10,0(25 \%$ of electricity), then at $\mathrm{pH}$ equal 4,0-6,0 (75\% of electricity ), aspen sawdust at $\mathrm{pH}=4,0-6,0$, the anode density of current is $0,125 \mathrm{kA} / \mathrm{m}^{2}$, the initial concentration of sodium chloride is $30,0 \mathrm{~kg} / \mathrm{m} 3$ of electrolyte, quantity of electricity is $0,9 \mathrm{kA} \cdot \mathrm{h} / \mathrm{kg}$ of raw materials.

After the electrochemical treatment of rye straw, birch and aspen sawdust, are identified reducing substances $(6,0$ $6,3 \mathrm{wt} . \%$ of the raw materials), glucose $\left(4,5-5,0 \mathrm{wt} . \%\right.$ of the raw materials), oxygen-containing compounds of chlorine ( $\mathrm{ClO}^{-}$of less than $0,001 \mathrm{~kg} / \mathrm{m}^{3}$ electrolyte, $\mathrm{ClO}_{3}{ }^{-}$is $0,014-0,019 \mathrm{~kg} / \mathrm{m}^{3}$ electrolyte), the mass of the residual solid (60-80 wt.\% of raw material), ruthenium and titanium (the absence).

The method is planned for using in a forage production on purpose of eliminate the imbalance of sugars in a fodder diet of agricultural animals.

Keywords: electrolysis, oxidation, straw, wood sawdust, reducing substances, glucose.

\section{References}

1. Avrutskaia I.A., Mukhina I.B., Arkhipova T.A. Elektrokhimiia, 1996, vol. 32, no. 1, pp.75-78. (in Russ.).

2. Ruzinov L.P. Planirovanie eksperimenta $v$ khimii i khimicheskoi tekhnologii. [The design of experiments in chemistry and chemical technology]. Moscow, 1980, 280 p. (in Russ.).

3. Vyrodova L.P., Morozova S.F., Degtiareva N.N. Sbornik trudov VNII Gidroliz. [Proceedings of the Institute of Hydrolysis]. Leningrad, 1987, pp. 45-52. (in Russ.).

4. Ziablitseva E.V., Riattel' A.V., Ziablitseva M.P., Lobastova E.V. Sovremennye tverdofaznye tekhnologii: teoriia, praktika i innovatsionnyi menedzhment. [Modern solid-phase technology: theory, practice and innovation management]. Tambov, 2010, pp. 249-251. (in Russ.).

5. Patent 2352140 (RU). 2009. (in Russ.).

6. Patent 2352184 (RU). 2009. (in Russ.).

Received July 31, 2013

\footnotetext{
* Corresponding author.
} 